\title{
MULTIPLE VIRUS INFECTIONS AND THE CHARACTERISTICS OF CHRONIC BEE PARALYSIS VIRUS IN DISEASED HONEY BEES
} (APIS MELLIFERA L.) IN CHINA

\author{
Yan Y. Wu $\mathbf{u}^{1,3}$ \\ Hui R. Jia ${ }^{1,3}$ \\ Qiang Wang ${ }^{1}$ \\ Ping L. Dai ${ }^{1}$ \\ Qing Y. Diao ${ }^{1}$ \\ Shu F. Xu ${ }^{1}$ \\ Xing Wang ${ }^{2}$ \\ Ting Zhou ${ }^{1 *}$
}

'Key Laboratory of Pollinating Insect Biology, Ministry of Agriculture, Institute of Apicultural Research, Chinese Academy of Agricultural Sciences, Beijing 100093, China

Beijing Management Station of Apiculture and Sericulture, Beijing 100029, China

${ }^{3}$ Yan Y. Wu and Hui R. Jia contributed equally to the article.

\section{Abstract}

China has the largest number of managed honey bee colonies globally, but there is currently no data on viral infection in diseased $A$. mellifera L. colonies in China. In particular, there is a lack of data on chronic bee paralysis virus (CBPV) in Chinese honey bee colonies. Consequently, the present study investigated the occurrence and frequency of several widespread honey bee viruses in diseased Chinese apiaries, and we used the reverse transcription-polymerase chain reaction (RT-PCR) assay. Described was the relationship between the presence of CBPV and diseased colonies (with at least one of the following symptoms: depopulation, paralysis, dark body colorings and hairless, or a mass of dead bees on the ground surrounding the beehives). Phylogenetic analyses of CBPV were employed. The prevalence of multiple infections of honey bee viruses in diseased Chinese apiaries was $100 \%$, and the prevalence of infections with even five and six viruses were higher than expected. The incidence of CBPV in diseased colonies was significantly higher than that in apparently healthy colonies in Chinese A. mellifera aparies, and CBPV isolates from China can be separated into Chinese-Japanese clade 1 and 2 . The results indicate that beekeeping in China may be threatened by colony decline due to the high prevalence of multiple viruses with CBPV.

Keywords: Apis mellifera L, China, chronic bee paralysis virus (CBPV), diseased honey bees, multiple viruses, phylogeny.

\section{INTRODUCTION}

Honey bees (Apis mellifera L.) are one of the most important and economically valuable pollinators of crops worldwide and are the most commonly managed pollinator species. Colonies of $A$. mellifera serve as biological indicators and provide invaluable data on the environmental and ecological impacts of particular factors on nature in general (Celli and Maccagnani, 2003). However, the abundance of honey bees is currently declining (vanEngelsdorp et al., 2011). The possible reasons for this decline are pathogens and pesticides (Vejsnæs et al., 2010). To date, at least 18 viruses have been reported in honey bees colonies (de Miranda et al., 2013) with the following viruses being the most common: deformed wing virus (DWV), black queen cell virus (BQCV), Israeli acute paralysis virus (IAPV), sacbrood virus (SBV), acute bee paralysis virus (ABPV), Kashmir bee virus (KBV), and chronic bee paralysis virus (CBPV). Multiple viral infections in honey bees have been reported in several countries (Berényi et al., 2006; Todd et al., 2007; Chen et al., 2011; Morimoto et al., 2012). Multiple viral infections are considered to 
be the cause of severe disease in honey bees particularly when accompanied with other stressors, such as Varroa destructor and Nosema infection, intoxication, poor nutrition, or cold weather (Allen and Ball, 1996; Chantawannakul et al., 2006). Thus, monitoring the occurrence and frequency of these viruses is vital for maintaining successful apiaries.

It has been reported that the following viruses can be present in apparently healthy honey bee colonies: DWV, BQCV, IAPV, SBV, ABPV, and KBV (Berényi et al., 2006; Ai et al., 2012; Morimoto et al., 2012; Yang et al., 2013; Jia et al., 2014). The majority of DWV infected bees were asymptomatic, while bees with high titres of the virus usually show overt infection, especially in Varroa infested colonies (Kojima et al., 2011; de Miranda and Genersch, 2010; de Miranda et al., 2013). Sacbrood virus, which can propagate in apparently healthy adult honey bees, primarily results in larval death (Berényi et al., 2006; Ai et al., 2012). Although BQCV clinically affects the pupae of the queen, it is commonly detected in apparently healthy adult bees, rather than in larvae or pupae (Kajobe et al., 2010). The description for ABPV, KBV, and IAPV is that of a complex of closelyrelated viruses in honey bees, with a predominantly sub-clinical etiology of honey bees (de Miranda and Genersch, 2010).

Infection with CBPV has been suggested as a significant factor that impacts on honey bee health (Bailey et al., 1963; Bailey and Woods, 1977; Ball, 1996; Ribière et al., 2007). A previous study in our laboratory reported that healthy honey bees injected with the purified preparation of CBPV from $A$. mellifera colonies (which were naturally affected with this viral type) showed paralytic symptoms after 4 days and death after 5 days. The mean mortality rate for the tested groups was nearly $100 \%$ at 10 days after injection (7.5\% for the control group) (Feng et al., 1986). These results are partially consistent with results from other studies (Bailey et al., 1963; Bailey and Woods, 1977; Ball, 1996). Relative to the six aforementioned viruses, CBPV has been shown to have a lower prevalence in many countries (Kajobe et al., 2010; Kojima et al., 2011 Yang et al., 2013). The symptoms of CBPV infected bees include a trembling motion of the wings and bodies of adult bees, and diseased bees often crawl on the ground. Some bees are greasy, have dark body colorings, and a hairless appearance. They become flightless and die in a few days (Morimoto et al., 2012). However, the relationship between the presence of CBPV and overt infection remains controversial. Ribière et al. (2002) reported no relationship between CBPV and overt infection in France.
In contrast, several studies have reported a higher incidence of CBPV in diseased honey bee colonies compared to apparently healthy colonies (Berényi et al., 2006; Cox-Foster et al., 2007; Todd et al., 2007; Morimoto et al., 2012; Yang et al., 2013). The samples infected with CBPV in these reports (fewer than 10 samples in each report), though, were too small to reach a final conclusion about the high incidence of CBPV in diseased honey bees.

China has the largest number of bee colonies (approximately 8.5 million) (Li, 2014) worldwide with the dominant honey bee species being $A$. mellifera ligustica. Epidemiological information on honey bee viruses is essential for both China and nearby countries affiliated with Chinese beekeeping activities.

With the exception of CBPV, the isolates of other common honey bee viruses (including DWV, BQCV, IAPV, SBV, ABPV, and KBV) from China, were found to belong to separate Chinese clades and showed the phylogenetic characteristic consistent with geographic separation (Yang et al., 2013; Li, 2014). There are currently only six CBPV isolates from Chinese A. mellifera colonies (Yang et al., 2013). These isolates could not be grouped into separate clusters. This small number of CBPV isolates is not sufficient to determine a clear relationship between the CBPV isolates in China and those in other countries. Furthermore, the CBPV tends to be isolated from diseased honey bee colonies (Allen and Ball, 1996; Berényi et al., 2006; Cox-Foster et al., 2007; Todd et al., 2007; Morimoto et al., 2012; Yang et al., 2013). It is necessary to investigate honey bee viruses in a broader number of diseased $A$. mellifera colonies in China.

Honey bee viral diseases are usually associated with Varroa mites and Nosema spp. infection. In North China, the general parasitic rate of Varroa mites on bees from July-August is the highest, and that from January-February is the lowest. Nosema spp. infection of this region from April-May is the highest, and that from January-February is the lowest. In South China, the parasitic rate of Varroa mites on bees in May and June is the highest, and that in December and January is the lowest. Nosema spp. infection of this region in March and April is the highest, and that in December and January is the lowest.

In the present study, the occurrence and frequency of seven common honey bee viruses (DWV, BQCV, IAPV, SBV, ABPV, KBV, and (BPV) were surveyed by RT-PCR. The difference in the incidence of a single virus in $A$. mellifera colonies was determined by comparing apparently healthy and diseased colonies 
in China. In addition, the phylogenetic relationships between RNA-dependent RNA polymerase (RdRp) proteins encoded by CBPV were analysed.

\section{MATERIAL AND METHODS}

\section{Honey bee samples}

Throughout China, beekeepers have reported serious colony declines in their apiaries. Beekeepers have even experienced losses of 10 colonies or more. Newly dead honey bees from one randomly tion on the level of these two kinds of mite infestations was also given by beekeepers. Each sample contained 30 to 50 honey bees. Fifteen bees from each sample were used for Nosema spp. detection which was based on the procedure described by Yang et al. (2013).

\section{RNA extraction}

Fifteen adult worker bees from each sample were homogenised in $\mathrm{TRIzol}^{\circledR}$ reagent (Invitrogen, Carlsbad, CA), and total RNA was extracted following

List of primers used for the detection of honey bee viruses

\begin{tabular}{|c|c|c|c|}
\hline Target & Sequence of primer $\left(5^{\prime}-3^{\prime}\right)$ & $\begin{array}{c}\text { Length } \\
\text { of product (bp) }\end{array}$ & Reference \\
\hline IAPV & $\begin{array}{l}\text { GGT GCC TAT TTA GGG TGA GGA } \\
\text { GGG AGT ATT GCT TTC TTG TTG TG }\end{array}$ & 158 & Sguazza et al., 2013 \\
\hline DWV & $\begin{array}{l}\text { TGG TCA ATT ACA AGC TAC TTG G } \\
\text { TAG TTG GAC CAG TAG CAC TCA T }\end{array}$ & 269 & Sguazza et al., 2013 \\
\hline SBV & $\begin{array}{l}\text { CGT AAT TGC GGA GTG GAA AGA TT } \\
\text { AGA TTC CTT CGA GGG TAC CTC ATC }\end{array}$ & 342 & Sguazza et al., 2013 \\
\hline ABPV & $\begin{array}{l}\text { GGT GCC CTA TTT AGG GTG AGG A } \\
\text { ACT ACA GAA GGC AAT GTC CAA GA }\end{array}$ & 460 & Sguazza et al., 2013 \\
\hline BQCV & $\begin{array}{l}\text { CTT TAT CGA GGA GGA GTT CGA GT } \\
\text { GCA ATA GAT AAA GTG AGC CCT CC }\end{array}$ & 536 & Sguazza et al., 2013 \\
\hline CBPV & $\begin{array}{l}\text { AAC CTG CCT CAA CAC AGG AAC } \\
\text { ACA TCT CTT CTT CGG TGT CAG CC }\end{array}$ & 774 & Sguazza et al., 2013 \\
\hline KBV & $\begin{array}{l}\text { ATGACGATGATGAGTTCAAG } \\
\text { AATTGCAAGACCTGCATC }\end{array}$ & 290 & Shen et al., 2005 \\
\hline
\end{tabular}

selected diseased colony (with at least one of the symptoms, including depopulation, paralysis, dark body colorings and hairless bodies, and/or mass dead bees on the ground surrounding the beehives) per apiary were collected. A sample from an apparently healthy colony (collected in the apiaries in which there was no colony with significant losses) from another apiary in the same city and the same month was also randomly selected. The worker bees from the apparently healthy colonies were alive and collected from brood nests inside the hives. Each colony was sampled only once. Six diseased colonies and six apparently healthy colonies were randomly selected from each Chinese province, respectively. A questionnaire was used to collect information about the tested colonies when the samples were selected. All samples were collected, visually examined for Varroa destructor mites and Tropilaelaps mites, and sent by post to the Key Laboratory of Pollinating Insect Biology (Beijing) by the beekeepers. Informa- the manufacturer's standard protocol (EastepTM Universal RNA Extraction Kit, Promega, Madison, WI, USA). The RNA samples were stored at $-80^{\circ} \mathrm{C}$.

\section{Reverse transcription-polymerase chain reaction (RT-PCR) amplification}

The occurrence and frequency of seven bee viruses were detected by RT-PCR. The virus specific primers were based on the previous reports for DWV, BQCV, IAPV, SBV, ABPV, and CBPV (Sguazza et al., 2013), and KBV (Shen et al., 2005) (Tab. 1). The reaction mixture and thermal cycling profiles of cDNA synthesis (Reverse Transcription System, Promega, Madison, WI) and the amplification, were performed as previously described (Sguazza et al., 2013). A negative and a positive DNA control were performed for each PCR reaction. The amplified bands were compared with the positive PCR products by electrophoresis on $2.0 \%$ agarose. Positive identification was confirmed by sequencing PCR products. 
Sequence of amplification fragments of each virus was aligned with the reported sequences of DWV, $B Q C V, I A P V, S B V, A B P V, K B V$ and CBPV in the GenBank database.

\section{Phylogenetic analyses of CBPV}

A phylogenetic tree of CBPV isolates from A. mellifera in China, was constructed. A total of 392 bp sequences (bases 958 - 1349) encoding a putative RNA-dependent RNA polymerase (RdRP) domain in the open reading frame 3 (ORF 3 ) of RNA segment 1 of CBPV were sequenced. The primer sets (F: TAYGAGYGATTTYYTTGRGATCGAYTTCGCT and R: TGTAYTCGRCCTCATTRACGACRTTAGC) were based on previous reports (Olivier et al., 2008; Yang et al. 2013). All sequences were aligned using the MUSCLE program (Edgar, 2004), and the Kimura 2-parameter method with a gamma distribution selected as the best-fit substitution model. The total lengths of these alignments was $325 \mathrm{bp}$. The equivalent sequences of the Hepatitis C virus (AB207801) was used as an outgroup. Phylogenetic analysis was conducted using the Neighbour-Joining (NL) method and a bootstrap value of 1000 replicates in MEGA5.

\section{Statistical analysis}

The relationships between the incidence of each honey bee virus (DWV, BQCV, IAPV, SBV, ABPV, KBV, and (BPV) and the diseased colonies, were evaluated with the Chi-square test. P-values below 0.05 were considered significant. All statistical analyses were conducted using SPSS 17.0 (SPSS Inc., Chicago, IL).

\section{RESULTS}

\section{The occurrence of the various seven viruses in} diseased honey bees

A total of 240 samples, from 20 Chinese provinces (South China: the provinces of Hunan, Hubei, Anhui, Sichuan, Guangzhou, Guizhou, Jiangsu, Jiangxi, Zhejiang, and Fujian; North China: the provinces of Henan, Hebei, Heilongjiang, Jilin, Liaoning, Gansu, Shaanxi, Shanxi, Shandong, and Beijing city), were submitted by beekeepers for analysis between January 2013 and December 2013. All samples were infected with multiple viruses. Six common honey bee viruses were detected, but ABPV was not detected. In diseased colonies, the most prevalent viruses were IAPV (99.17\%), DWV (98.33\%), SBV (98.33\%), and CBPV (96.67\%), followed by BQCV (63.33\%), and KBV (13.33\%). In apparently healthy colonies, the data was similar to that in the diseased colonies except for CBPV (5.83\%). The most prevalent viruses were IAPV (94.17\%), DWV (92.50\%), SBV (92.50\%), BQCV (58.33\%), and KBV (10.83\%).

There were 120 samples collected from diseased colonies. The following is a list of the months with the amount of collected samples noted after each month: January 9, February 10, March 10, April 12, May 10, June 11, July 10, August 10, September 10, October 9, November 10, and December 9. In China, there are four seasons (spring: March May; summer: June - August; autumn: September - November; winter: December - February). The amount of samples in each season was 32, 31, 29 , and 28 from spring to winter, respectively. No significant seasonal variance was identified in the detection frequency of the investigated viruses during the course of the year (Chi ${ }^{2}$ DWV $p=0.389$; BQCV $p=0.987 ;$ IAPV $p=0.435 ;$ SBV $p=0.410 ; \mathrm{KBV}$ $p=0.281$ ). Generally, spring, summer, and autumn are active beekeeping seasons, and winter is the non-active season in China. There were 92 infected samples in active beekeeping seasons and 28 in the non-active season. The incidence of each virus (DWV, BQCV, IAPV, SBV, KBV, or CBPV) did not significantly differ in active and non-active beekeeping seasons (Chi ${ }^{2}$, DWV $p=0.955$; BQCV $p=1.000$; IAPV $p=1.000 ;$ SBV $p=0.950 ; \mathrm{KBV} p=0.156 ; \mathrm{CBPV}$ $p=1.000)$.

According to the reports of the beekeepers, all of the investigated colonies (240 colonies) were infested with Varroa destructor. Of the apiaries surveyed, $72.5 \%$ were host to Tropilaelaps mites. The infestation level with the two kinds of mites was low, because these colonies were all regularly treated with acaricide and sublimed sulphur. There was no significant correlation between the level of Varroa destructor mite infestation and the pattern of sampling in this study. Typical symptoms of chronic bee paralysis were observed in some of the collected, newly-dead bees (see supplementary data).

Nosema ceranae was indentified in $67.5 \%$ of the samples from diseased colonies and in $62.5 \%$ from apparently healthy colonies. Nosema apis was not detected in all samples. There was no significant difference in the incidence of the investigated honey bee virus between $N$. ceranae infected samples and non-infected samples from diseased colonies collected from South China (Ch², DWV $p=0.874$; BQCV $p=0.943$; IAPV $p=0.653$; SBV $p=0.995$; KBV $p=0.227 ;$ CBPV $p=1.000)$ or North China $\left(\mathrm{Ch}^{2}\right.$, DWV $p=0.971 ;$ BQCV $p=0.932 ;$ IAPV $p=0.771$; SBV $p=0.870 ; \mathrm{KBV} p=0.439 ; \operatorname{CBPV} p=0.916)$. 


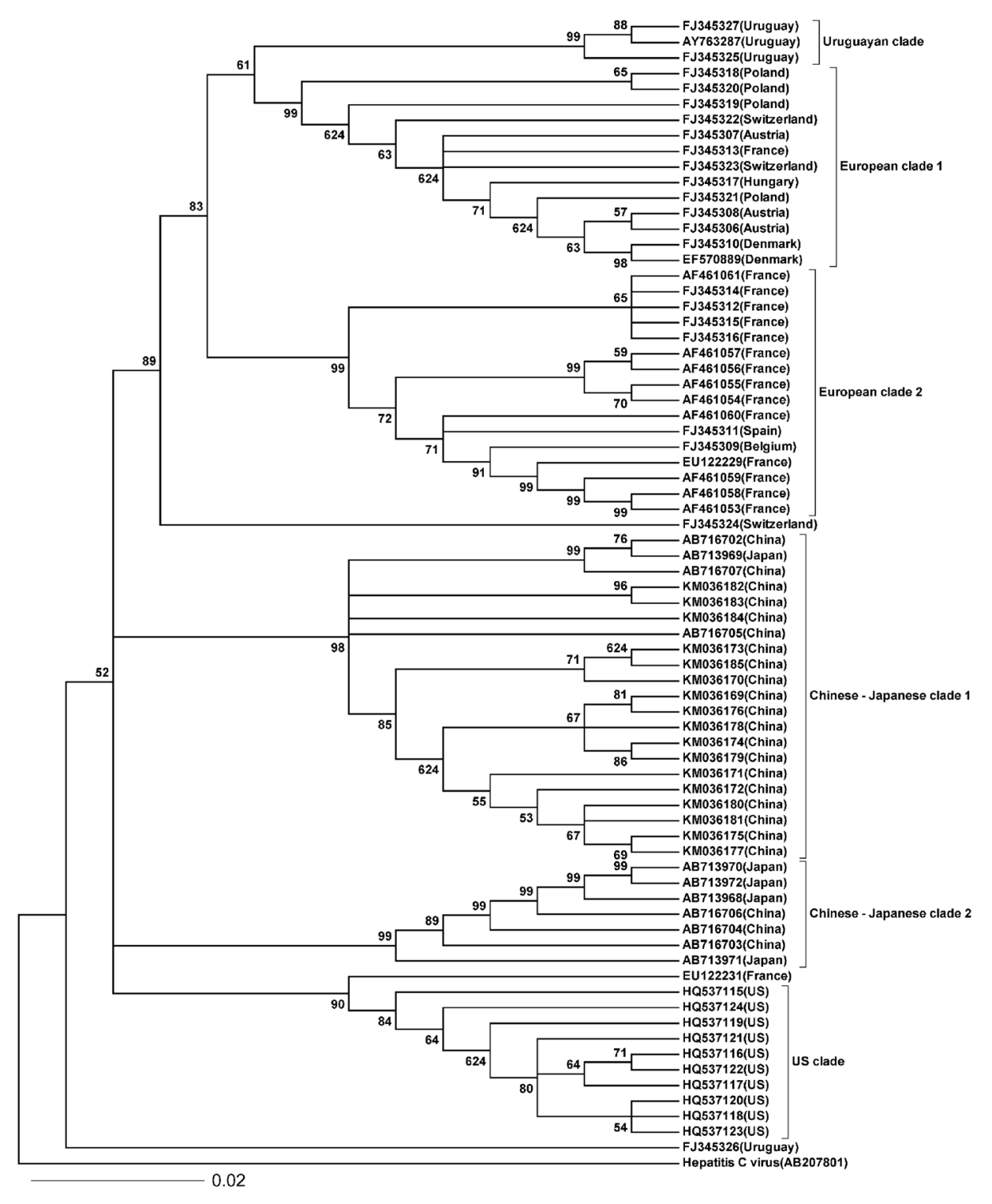

Fig. 1. Phylogenetic relationship of chronic bee paralysis virus (CBPV) isolates from China and other countries. The condensed phylogenetic tree based on alignment of the putative RdRP gene sequences of Chinese, Japanese, mainland US, European, and Uruguayan. The Neighbour-Joining (NJ) method was used. Hepatitis C virus (AB207801) was used as an outgroup to root the tree. The number of each node represents the bootstrap value resulting from 1000 replicates, and the nodes supported by bootstrap values $>50$ are shown. Each isolate is indicated by its accession number, followed by the collected locations.

\section{Pattern of multiple virus infection in diseased honey bees}

Among the infected samples, $51.67 \%$ showed coinfection with five viruses (DWV/BQCV/IAPV/SBVI CBPV and DWV/IAPV/SBV/KBV/CBPV), 33.33\% showed co-infection with four viruses (DWV/IAPV/ SBV/CBPV and DWV/BQCV/IAPV/SBV), $10.83 \%$ showed co-infection with six viruses (DWV/BQCV/ IAPV/SBV/KBV/CBPV), and the remaining colonies $(4.17 \%)$ showed co-infection with three viruses (IAPV/SBV/CBPV, DWV/IAPV/CBPV, BQCV/IAPV/ SBV, DWV/BQCV/IAPV, and DWV/SBV/CBPV). In addition, the most prevalent co-infection patterns were DWV/BQCV/IAPV/SBV/CBPV (49.17\%) for five viruses, and DWV/IAPV/SBV/CBPV (31.67\%) for four viruses.

The incidence of each virus in diseased and apparently healthy colonies

The incidence of CBPV in diseased colonies (116 infected samples out of 120 samples from diseased colonies, 96.67\%) was significantly higher than that in apparently healthy colonies (5.83\%) $\left(\mathrm{Chi}^{2}, \mathrm{p}=0.000\right)$. The incidence of other viruses 
(DWV 98.33\%, BQCV 63.33\%, IAPV 99.17\%, SBV 98.33\%, and KBV 13.33\%) did not significantly differ in the diseased and apparently healthy colonies (DWV 92.50\%, BQCV 58.33\%, IAPV 94.17\%, SBV 92.50\%, and KBV 10.83\%) (Chi², DWV $p=0.064$; BQCV $p=0.508 ;$ IAPV $p=0.072 ;$ SBV $p=0.064$; $\operatorname{KBV} p=0.552)$.

\section{Phylogenetic relationship of CBPV isolates from different countries}

To analyse the phylogeny of Chinese CBPV isolates, a region of the putative RdRP coding sequences was analysed based on the availability of this sequence in most isolates from different countries. It was found that 17 isolates had sequence variations (KM036169 - KM036185, see Fig. 1). The phylogeny of Chinese, Japanese, Uruguayan, mainland US, and European CBPV isolates was constructed using the NeighbourJoining (NJ) method and the putative RdRP coding sequences (Fig. 1). The European isolates were grouped into two major clusters (European clade 1 and 2), except for the two isolates, EU122231 and FJ345324. The mainland US isolates and Uruguayan isolates (except of FJ345326) formed independent clades, the US clade and the Uruguayan clade, respectively, as previously reported (Blanchard et al., 2009; Chen et al., 2011; Morimoto et al., 2012; Yang et al., 2013). All of the 17 CBPV isolates included in the present study, along with three additional Chinese isolates (AB716702, AB716705 and AB716707; Yang et al., (2013)), and one Japanese isolate (AB713969; Morimoto et al., 2012) formed a mixed clade; the Chinese-Japanese clade 1. In addition, four Japanese isolates (AB713968, AB713970, $A B 713971$, and $A B 713972 ;$ Morimoto et al., (2012)) and three Chinese isolates (AB716703, AB716704, and AB716706; Yang et al., (2013)) formed the Chinese-Japanese clade 2. Finally, two new clades (Chinese-Japanese clade 1 and 2) formed the Asian clade. Although there were several exceptions (EU122231 and FJ345324), the Asian, European, mainland US, and Uruguayan clades showed the trend of geographic separation.

\section{DISCUSSION}

High prevalence of multiple virus infections in diseased honey bees in China

The pattern of multiple viral infections in diseased A. mellifera apiaries in China is unique to this region. When compared with data from other countries, the prevalence of multiple viral infections was extremely high, specifically for co-infection with five and six viruses. These patterns have seldom been reported in other countries, and rarely in apparently healthy colonies. Interestingly, bees infected with two viruses or one virus were not found in China.

Moreover, the multiple virus infection of DWV/ IAPV/SBV/CBPV was surprisingly consistent in Chinese diseased samples (all these viruses were detected in $95.83 \%$ of diseased colonies). In other reports, the largest number of viruses in a multiple infection was 5 ( $1 \%$ of the samples) and the smallest number was 1 (8\%) based on a report from Austria (Berényi et al., 2006), 5 (3.45\%), and free of viruses $(82.76 \%)$ based on a report from Japan (Morimoto et al., 2012), 4 (< 16.67\%) and 1 (4.60\%) based on a report from New Zealand (Todd et al., 2007), and 6 (25\%) and 1 (25\%) based on a report from the USA (Cox-Foster et al., 2007). The current study showed that Varroa and associated viruses were detected in most of the samples, and the Tropilaelaps spp. infestation was widespread (72.5\%). Low levels of Varroa and Tropilaelaps spp. infestations were reported by beekeepers, but beekeepers' experiences might lack accuracy. Considering the impact of Tropilaelaps spp., Varroa, and associated viruses in honey bees, investigating colonies for the level of these two kinds of mite infestations should be conducted by researchers in the future. In addition, there is a similar incidence of $N$. ceranae in apparently healthy (62.5\%) and diseased colonies (67.5\%) here. The examination of only 15 bees might underestimate the true incidence of this microsporidium. The level of Nosema infection was not investigated in this study. Nosema apis appears to be associated with the pathogenesis of BQCV outbreaks (Allen and Ball, 1996). The relationship between $N$. ceranae and BQCV, and their role in colony losses also needs further study. It is noteworthy that the SBV observed in the current study appears unusual. This virus seems to be widespread in Chinese $A$. mellifera apiaries, but this virus causes covert infections, which is consistent with reports referring to Chinese areas (Ai et al., 2012; Yang et al., 2013; Jia et al., 2014). However, sacbrood virus can also be a cause of colony depopulation, and the symptoms in the colonies might have been ignored by beekeepers in this study. In addition, the relative viral load from diseased colonies was 10-126 folds higher than in bees from apparently healthy colonies (Bailey et al., 1963; Berényi et al., 2006). Thus, viral load may determine whether the infection is covert or overt. An investigation into the symptoms of SBV infection and viral load in diseased and apparently healthy colonies is still needed. 
Previous studies on apiaries outside of China have reported occasional co-infection with four, five, and six honey bee viruses. But the most prevalent pattern of multiple viral infection in diseased and apparently healthy colonies has been reported to be co-infection with two and three viruses (Berényi et al., 2006; Todd et al., 2007; Morimoto et al., 2012). The results of the present study show that the prevalence of multiple viral infections in diseased honey bees in China, is one of the highest in the world. The viral analysis of diseased colonies in this study provides a more informative picture of the prevalence of multiple viral infections in China. The results of the present study suggest that beekeeping in China may be threatened by colony decline due to the high prevalence of multiple viruses. Solutions must be found to avoid colony decline within Chinese $A$. mellifera colonies. Our study results also suggest that beekeepers in China or other counties with a close relationship with Chinese beekeeping activities, ought to be cautious and diligent about virological analysis before importing and purchasing bee colonies and products.

\section{The characteristics of CBPV in diseased colonies in China}

Our results demonstrate that five common honey bee viruses (DWV, BQCV, IAPV, SBV, and KBV), but not CBPV, resulted in a similar incidence, no matter whether in diseased or apparently healthy colonies, and that the 5 viruses induced covert infections in apparently healthy colonies in China. The phylogenetic characterisation of the five viruses' isolates (DWV, BQCV, IAPV, SBV, and KBV) has been widely studied due to the high occurrence and global prevalence of these viruses (Todd et al., 2007; Yang et al., 2013), while data on CBPV isolates from different countries remains limited, particularly in China. Thus, the current study also focused on the characteristics of CBPV in diseased colonies in China. The incidence of CBPV in diseased colonies was significantly higher than in what were apparently healthy colonies. Previously published data, in conjunction with the findings of the present study, provide further support for this hypothesis. Our previous work (Jia et al., 2014) showed that the pattern of multiple viral infections of DWV/BQCV/ IAPV/SBV was consistent (100\% of the samples) in apparently healthy $A$. mellifera colonies of randomly selected apiaries from four counties in Beijing while the diseased colonies showed different co-infection (DWV/BQCV/IAPV/SBV/CBPV). Such a pattern indicates that the difference between the two popu- lations was most likely due to the presence of CBPV. In addition, Ai et al. (2012, 6\%), and Yang et al. (2013,0\%) and the present study (3.33\%), found a low level of CBPV infection in apparently healthy Chinese $A$. mellifera colonies, which supports the findings in other countries (Berényi et al., 2006; Sanpa and Chantawannakul, 2009; Kajobe et al., 2010). In contrast, CBPV was found in 6 out of 6 samples (100\%) of diseased $A$. mellifera worker bees in Chinese apiaries in a previous study (Yang et al., 2013), and in 116 of 120 diseased samples $(96.67 \%)$ in the present study.

In previous reports, Asian (Chinese and Japanese) isolates did not form mixed clades as there were only six Chinese isolates (Yang et al., 2013). The results of the current study show that 17 CBPV isolates clustered in the same clade (the Chinese-Japanese clade 1). This finding indicates that for the first time, Chinese isolates can be separated into two clades (the Chinese-Japanese clade 1 and 2). In addition, the results of the present study show that one CBPV isolate from Japan (AB713696), which is close to the mainland US and Japanese isolates (Morimoto et al., 2012), is clustered in the Chinese-Japanese clade 1. In summary, CBPV was rarely detected in apparently healthy $A$. mellifera colonies, yet present in nearly all diseased Chinese $A$. mellifera colonies. Toward minimising the impact of viral pathogens, diseased or dead honey bees in apiaries should be collected on a regular basis (and either buried or burned). This may help to eliminate an important viral source that could result in further disease propagation. Routine strategies for detection of honey bee viruses, especially CBPV, should be considered by beekeepers before purchasing honey bees or bee bread. In this study, 15 bees from the brood nest were examined, which was based on previous studies (de Miranda et al., 2013; Yang et al., 2013), while the foragers were reported to have a higher level of CBPV infection than young bees from the inside of hives (Bacandritsos et al., 2010). Therefore, the prevalence of CBPV in apparently healthy colonies might actually be higher. In addition, visible symptoms of CBPV infection have also been reported by beekeepers because it was difficult and costly for researchers to reach each involved apiary in China. The early stage of CBPV infection, which was less obvious, was excluded from this study. Further researches are required to investigate the symptoms of CBPV infection by researchers and to detect the viral load in more forager bees from diseased and apparently healthy colonies in China. 


\section{CONCLUSIONS}

The prevalence of multiple virus infections is high in A. mellifera colonies in China, especially a prevalence of five and six viruses at a time in diseased colonies. Except CBPV, the incidence of DWV, BQCV, IAPV, SBV, ABPV, or KBV showed no significant difference between diseased (with at least one of the symptoms, including depopulation, paralysis, dark body colorings and hairless, or mass dead bees on the ground surrounding the beehives) and apparently healthy colonies; and CBPV, the isolates from China can be separated into Chinese-Japanese clade 1 and 2.

\section{ACKNOWLEDGMENTS}

We thank the editors and reviewers for their helpful comments on the earlier draft of this paper. This work was supported by grants from the National Natural Science Foundation of China (No. 31402148), the China Agriculture Research System projects (No. CARS-45-KXJ6) and the Agricultural Science and Technology Innovation Program (No. CAAS-ASTIP2015-IAR).

\section{REFERENCES}

Ai H., Yan X. Han R. (2012) Occurrence and prevalence of seven bee viruses in Apis mellifera and Apis cerana apiaries in China. Journal of Invertebrate Pathology 109(1): 160-164.

Allen M., Ball B. (1996) The incidence and world distribution of the honey bee viruses. Bee World 77: $141-162$

Bacandritsos N., Granato A., Budge G., Papanastasiou I., Roinioti E., Caldon M., Falcaro C., Gallina A., Mutinelli F. (2010) Sudden deaths and colony population decline in Greek honey bee colonies. Journal of Invertebrate Pathology. 105(3): 335-340.

Bailey L., Woods R. D. (1977) Two more small RNA viruses from honeybees and further observations on sacbrood and acute bee-paralysis viruses. The Journal of General Virology 37: 175-182.

Bailey L., Gibbs A. J., Woods R. D. (1963) Two viruses from adult honey bees (Apis mellifera Linnaeus). Virology 21: 390-395.

Ball B. V. (1996) Honeybee viruses: a cause for concern? Bee World 77: 117-119.

102
Berényi O., Bakonyi T., Derakhshifar l., Köglberger $H_{\text {., }}$ Nowotny N. (2006) Occurrence of six honey bee viruses in diseased Austrian apiaries. Applied and Environmental Microbiology 72(4): 2414-2420.

Blanchard P." Schurr F., Olivier V., Celle O., Antùnez K." Bakonyi T., Berthoud H., Haubruge E., Higes M., Kasprzak S., Koeglberger H., Kryger P., Thiéry R., Ribière M. (2009) Phylogenetic analysis of the RNA-dependent RNA polymerase (RdRp) and a predicted structural protein (pSP) of the chronic bee paralysis virus (CBPV) isolated from various geographic regions. Virus Research 144(1 2): 334-338.

Celli G., Maccagnani B. (2003) Honey bees as bioindicators of environmental pollution. Bulletin of Insectology 56: 137-139.

Chantawannakul P., Ward L., Boonham N., Brown M. (2006) A scientific note on the detection of honeybee viruses using real-time PCR (TagMan) in Varroa mites collected from a Thai honeybee (Apis mellifera) apiary. Journal of Invertebrate Pathology. 91 (1): 69-73.

Chen Y. P., Evans J. D., Pettis J. S. (201 1) The presence of chronic bee paralysis virus infection in honey bees (Apis mellifera $L$.) in the USA. Journal of Apicultural Research 50(2): 85-86.

Cox-Foster D. L., Conlan S., Holmes E. C., Palacios G., Evans J. D., Moran N. A., Quan P. L., Briese T., Hornig M., Geiser

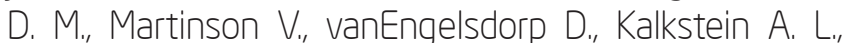
Drysdale A., Hui l., Zhai l., Cui L., Hutchison S. K., Simons I. F., Eqholm M., Pettis J. S., Lipkin W. I. (2007) A metagenomic survey of microbes in honey bee colony collapse disorder. Science 318(5848): 283-287.

de Miranda J., Genersch E. (2010) Deformed wing virus. Journal of Invertebrate Pathology 103: S48-S61.

de Miranda J. R., Bailey L., Ball B. V., Blanchard P., Budge G. E., Chejanovsky N., Chen Y. P., Gauthier L., Genersch E., de Graaf D. C., Ribière M., Ryabov E., De Smet L., van der Steen f. J. M. (2013) Standard methods for virus research in Apis mellifera. Journal of Apicultural Research, 52:4, $1-56$.

Edgar R. C. (2004) MUSCLE: Multiple sequence alignment with high accuracy and high throughput. Nucleic Acids Research 32(5): 1792-1797.

Feng F., Chen S. J., Xia L. J., Chen M., Fang Q. Y., Gao Y. J., Yin M. B. (1986) Studies on RNA and protein components of chronic bee paralysis virus. Chinese Journal of Virology 2: 175-180. 
jia H. R., Liu J. Z., Wang X., Wu Y. Y., Zhou T. (2014) Occurrence and prevalence of six bee viruses in Beijing. Chinese Journal of Applied Entomology 51: 772-780.

Kajobe R., Marris G., Budge G., Laurenson L., Cordoni G., Jones B., Wilkins S., Cuthbertson A. G., Brown M. A. (2010) First molecular detection of a viral pathogen in Ugandan honey bees. Journal of Invertebrate Pathology 104(2): 153-156.

Kojima Y., Toki T., Morimoto T., Yoshiyama M., Kimura K., Kadowaki T. (2011) Infestation of Japanese native honey bees by tracheal mite and virus from non-native European honey bees in Japan. Microbial Ecology 62(4): 895-906.

Li Z. G. (2014) Molecular detection, prevalence and transmission of Israeli acute paralysis virus and its effects on honey bee behaviors. Ph.D. dissertation. Zhejiang University. Hangzhou. 114 pp.

Morimoto T., Kojima Y., Yoshiyama M., Kimura K., Yang Y., Kadowaki T. (2012) Molecular identification of chronic bee paralysis virus infection in Apis mellifera colonies in Japan. Viruses 4(7): 1093-1103.

Olivier V., Blanchard P., Chaouch S., Lallemand P., Schurr $F_{. "}$ Celle O., Dubois E., Tordo N., Thiéry R., Houlgatte R., Ribière M. (2008) Molecular characterization and Phylogenetic analysis of chronic bee paralysis virus, a honey bee virus. Virus Research 132(1-2): 59-68.

Ribière M., Triboulot C., Mathieu L., Auriéres C., Faucon J. P., Péin M. (2002) Molecular diagnosis of chronic bee paralysis virus infection. Apidologie 33: 339-351.

Ribière M., Lallemand P., Iscache A.L., Schurr F., Celle O., Blanchard P., Olivier V., Faucon J. P. (2007) Spread of infectious chronic bee paralysis virus by honeybee
(Apis mellifera L.) feces. Applied and Environmental Microbiology 73(23): 7711-7716.

Sanpa S., Chantawannakul P. (2009) Survey of six bee viruses using RT-PCR in Northern Thailand. Journal of Invertebrate Pathology 100(2): 116-1 19.

Sguazza G. H., Reynaldi F. J., Galosi C. M., Pecoraro M. R. (2013) Simultaneous detection of bee viruses by multiplex PCR. Journal of Virological Methods 194(1-2): 102-106.

Shen M. L., Ositiguy C. N., Cox-Foster D. (2005) Intricate transmission routes and interactions between picornalike viruses (Kashmir bee virus and Sacbrood virus) with the honeybee host and the parasitic Varroa mite. Journal of General Virology 86: 2281-2289.

SPSS 17.0 SPSS Inc. Chicago, IL.

Todd J. H., de Miranda J. R., Ball B. V. (2007) Incidence and molecular characterization of viruses found in dying New Zealand honey bee (Apis mellifera) colonies infested with Varroa destructor. Apidologie 38: 354-367.

vanEngelsdorp D., Hayes J. J., Underwood R. M., Caron R. M., Pettis J. (2011) A survey of managed honey bee colony losses in the USA, fall 2009 to winter 2010. Journal of Apicultural Research 50: 1-10.

Vejsnæs F., Nielsen S. L., Kryger P. (2010) Factors involved in the recent increase in colony losses in Denmark. Journal of Apicultural Research 49(1): 109-1 10.

Yang B., Peng G., Li T., Kadowaki T. (2013) Molecular and phylogenetic characterization of honey bee viruses, Nosema microsporidia, protozoan parasites, and parasitic mites in China. Ecology and Evolution 3(2): 298-31 1. 
Supplementary data:

The presence of IAPV, DWV, SBV, BQCV, CBPV, KBV and ABPV in diseased A. mellifera colonies by RT-PCR

\begin{tabular}{|c|c|c|c|c|c|c|c|c|c|}
\hline Region & & IAPV & DWV & SBV & BQCV & CBPV & KBV & ABPV & $\begin{array}{l}\text { Symptom } \\
\text { of chronic bee } \\
\text { paralysis }\end{array}$ \\
\hline & Spring & & & & & & & & \\
\hline Hebei & Мar. & 1 & 1 & 1 & 0 & 1 & 0 & 0 & 1 \\
\hline Henan & Маг. & 1 & 1 & 1 & 1 & 1 & 0 & 0 & 1 \\
\hline Shaanxi & Mar. & 1 & 1 & 1 & 0 & 1 & 0 & 0 & 0 \\
\hline Shandong & Мar. & 1 & 1 & 1 & 1 & 1 & 0 & 0 & 0 \\
\hline Anhui & Маг. & 1 & 1 & 1 & 1 & 1 & 0 & 0 & 1 \\
\hline Guizhou & Мar. & 1 & 1 & 1 & 0 & 1 & 0 & 0 & 0 \\
\hline Hunan & Mar. & 1 & 1 & 1 & 1 & 1 & 0 & 0 & 0 \\
\hline Jiangxi & Mar. & 1 & 1 & 1 & 1 & 1 & 0 & 0 & 0 \\
\hline Zhejiang & Mar. & 1 & 1 & 1 & 0 & 1 & 0 & 0 & 0 \\
\hline Beijing & Apr. & 1 & 1 & 1 & 1 & 1 & 0 & 0 & 1 \\
\hline Gansu & Apr. & 1 & 1 & 1 & 1 & 0 & 0 & 0 & 0 \\
\hline Hebei & Арг. & 1 & 1 & 1 & 1 & 1 & 1 & 0 & 1 \\
\hline Jilin & Арг. & 1 & 1 & 1 & 0 & 1 & 0 & 0 & 1 \\
\hline Liaoning & Арг. & 1 & 1 & 1 & 1 & 1 & 0 & 0 & 1 \\
\hline Shandong & Арг. & 1 & 1 & 1 & 0 & 1 & 0 & 0 & 1 \\
\hline Shanxi & Арг. & 1 & 1 & 1 & 1 & 1 & 0 & 0 & 1 \\
\hline Anhui & Арг. & 1 & 1 & 1 & 0 & 1 & 0 & 0 & 0 \\
\hline Hubei & Apr. & 1 & 1 & 1 & 1 & 1 & 0 & 0 & 1 \\
\hline Hunan & Арг. & 1 & 1 & 1 & 0 & 1 & 0 & 0 & 0 \\
\hline Jiangsu & Apr. & 1 & 1 & 1 & 1 & 1 & 1 & 0 & 0 \\
\hline Jiangxi & Арг. & 1 & 1 & 1 & 0 & 1 & 0 & 0 & 0 \\
\hline Gansu & May & 1 & 1 & 1 & 1 & 1 & 1 & 0 & 0 \\
\hline Jilin & May & 1 & 1 & 1 & 0 & 1 & 1 & 0 & 1 \\
\hline Liaoning & May & 1 & 1 & 1 & 1 & 1 & 0 & 0 & 0 \\
\hline Shaanxi & May & 1 & 1 & 1 & 1 & 1 & 0 & 0 & 0 \\
\hline Anhui & May & 1 & 1 & 1 & 0 & 1 & 0 & 0 & 0 \\
\hline Fujian & May & 1 & 1 & 1 & 1 & 1 & 0 & 0 & 1 \\
\hline Hunan & May & 1 & 1 & 1 & 0 & 1 & 0 & 0 & 0 \\
\hline Sichuan & May & 1 & 1 & 1 & 1 & 1 & 0 & 0 & 1 \\
\hline Zhejiang & May & 1 & 1 & 1 & 1 & 1 & 0 & 0 & 1 \\
\hline \multirow[t]{3}{*}{ Heilongjiang } & May & 1 & 1 & 1 & 1 & 1 & 0 & 0 & 1 \\
\hline & No. of positive & 31 & 31 & 31 & 19 & 30 & 4 & 0 & 0 \\
\hline & Summer & & & & & & & & \\
\hline Gansu & Jun. & 1 & 1 & 1 & 1 & 1 & 1 & 0 & 1 \\
\hline Heilongjiang & Jun. & 1 & 1 & 1 & 0 & 1 & 0 & 0 & 0 \\
\hline Henan & Jun. & 0 & 1 & 1 & 0 & 1 & 0 & 0 & 0 \\
\hline Jilin & Jun. & 1 & 1 & 1 & 1 & 1 & 0 & 0 & 0 \\
\hline Liaoning & Jun. & 1 & 1 & 1 & 1 & 1 & 0 & 0 & 0 \\
\hline
\end{tabular}




\begin{tabular}{|c|c|c|c|c|c|c|c|c|c|}
\hline Shanxi & Jun. & 1 & 1 & 1 & 0 & 1 & 0 & 0 & 1 \\
\hline Guangdong & Jun. & 1 & 1 & 1 & 0 & 1 & 0 & 0 & 1 \\
\hline Guizhou & Jun. & 1 & 1 & 1 & 1 & 1 & 0 & 0 & 1 \\
\hline Hubei & Jun. & 1 & 1 & 1 & 0 & 1 & 0 & 0 & 0 \\
\hline Sichuan & Jun. & 1 & 1 & 1 & 1 & 1 & 1 & 0 & 0 \\
\hline Zhejiang & Jun. & 1 & 1 & 1 & 0 & 1 & 0 & 0 & 0 \\
\hline Beijing & Jul. & 1 & 1 & 1 & 1 & 1 & 0 & 0 & 1 \\
\hline Gansu & Jul. & 1 & 1 & 0 & 0 & 1 & 0 & 0 & 0 \\
\hline Hebei & Jul. & 1 & 1 & 1 & 1 & 1 & 0 & 0 & 1 \\
\hline Heilongjiang & Jul. & 1 & 1 & 1 & 0 & 1 & 0 & 0 & 0 \\
\hline Liaoning & Jul. & 1 & 1 & 1 & 1 & 1 & 0 & 0 & 1 \\
\hline Anhui & Jul. & 1 & 1 & 1 & 1 & 1 & 0 & 0 & 1 \\
\hline Fujian & Jul. & 1 & 1 & 1 & 1 & 0 & 0 & 0 & 0 \\
\hline Hubei & Jul. & 1 & 1 & 1 & 1 & 1 & 0 & 0 & 0 \\
\hline Hunan & Jul. & 1 & 1 & 1 & 1 & 1 & 1 & 0 & 1 \\
\hline Jiangxi & Jul. & 1 & 1 & 1 & 1 & 1 & 1 & 0 & 0 \\
\hline Gansu & Aug. & 1 & 1 & 1 & 1 & 1 & 1 & 0 & 1 \\
\hline Heilongjiang & Aug. & 1 & 1 & 1 & 1 & 1 & 0 & 0 & 1 \\
\hline jilin & Aug. & 1 & 1 & 1 & 1 & 1 & 0 & 0 & 0 \\
\hline Liaoning & Aug. & 1 & 1 & 1 & 0 & 1 & 0 & 0 & 0 \\
\hline Shanxi & Aug. & 1 & 1 & 1 & 1 & 1 & 0 & 0 & 1 \\
\hline Anhui & Aug. & 1 & 1 & 1 & 0 & 1 & 0 & 0 & 0 \\
\hline Hubei & Aug. & 1 & 1 & 1 & 1 & 1 & 0 & 0 & 0 \\
\hline Jiangsu & Aug. & 1 & 1 & 1 & 1 & 1 & 0 & 0 & 0 \\
\hline Jiangxi & Aug. & 1 & 1 & 1 & 0 & 1 & 0 & 0 & 0 \\
\hline \multirow[t]{3}{*}{ Zhejiang } & Aug. & 1 & 1 & 1 & 0 & 1 & 0 & 0 & 1 \\
\hline & No. of positive & 30 & 31 & 30 & 19 & 30 & 5 & 0 & 0 \\
\hline & Autumn & & & & & & & & \\
\hline Beijing & Sep. & 1 & 1 & 1 & 0 & 1 & 0 & 0 & 0 \\
\hline Heilongjiang & Sep. & 1 & 1 & 1 & 1 & 1 & 0 & 0 & 1 \\
\hline Henan & Sep. & 1 & 1 & 1 & 0 & 1 & 0 & 0 & 1 \\
\hline Jilin & Sep. & 1 & 1 & 1 & 1 & 1 & 0 & 0 & 0 \\
\hline Liaoning & Sep. & 1 & 1 & 1 & 1 & 1 & 0 & 0 & 1 \\
\hline Guizhou & Sep. & 1 & 1 & 1 & 1 & 1 & 0 & 0 & 1 \\
\hline Hunan & Sep. & 1 & 1 & 1 & 0 & 1 & 0 & 0 & 0 \\
\hline Jiangsu & Sep. & 1 & 1 & 1 & 1 & 1 & 0 & 0 & 0 \\
\hline Jiangxi & Sep. & 1 & 1 & 1 & 1 & 1 & 0 & 0 & 0 \\
\hline Sichuan & Sep. & 1 & 1 & 1 & 0 & 1 & 0 & 0 & 1 \\
\hline Hebei & Oct. & 1 & 1 & 1 & 1 & 1 & 0 & 0 & 1 \\
\hline Shaanxi & Oct. & 1 & 1 & 1 & 1 & 1 & 0 & 0 & 0 \\
\hline Shandong & Oct. & 1 & 1 & 1 & 1 & 1 & 0 & 0 & 0 \\
\hline Shanxi & Oct. & 1 & 1 & 1 & 1 & 1 & 1 & 0 & 1 \\
\hline Anhui & Oct. & 1 & 0 & 1 & 1 & 0 & 0 & 0 & 0 \\
\hline Fujian & Oct. & 1 & 1 & 1 & 1 & 1 & 0 & 0 & 0 \\
\hline Guangdong & Oct. & 1 & 1 & 1 & 0 & 1 & 0 & 0 & 1 \\
\hline Jiangsu & Oct. & 1 & 1 & 1 & 1 & 1 & 1 & 0 & 0 \\
\hline
\end{tabular}




\begin{tabular}{|c|c|c|c|c|c|c|c|c|c|}
\hline Zhejiang & Oct. & 1 & 1 & 1 & 1 & 1 & 0 & 0 & 1 \\
\hline Beijing & Nov. & 1 & 1 & 1 & 0 & 1 & 1 & 0 & 0 \\
\hline Gansu & Nov. & 1 & 1 & 1 & 1 & 1 & 0 & 0 & 1 \\
\hline Heilongjiang & Nov. & 1 & 1 & 1 & 1 & 1 & 0 & 0 & 1 \\
\hline Jilin & Nov. & 1 & 1 & 1 & 1 & 1 & 0 & 0 & 1 \\
\hline Shanxi & Nov. & 1 & 1 & 1 & 1 & 1 & 1 & 0 & 1 \\
\hline Guangdong & Nov. & 1 & 1 & 1 & 0 & 1 & 0 & 0 & 0 \\
\hline Guizhou & Nov. & 1 & 1 & 1 & 1 & 1 & 0 & 0 & 0 \\
\hline Hubei & Nov. & 1 & 1 & 1 & 0 & 1 & 1 & 0 & 1 \\
\hline Hunan & Nov. & 1 & 1 & 1 & 0 & 1 & 0 & 0 & 0 \\
\hline \multirow[t]{3}{*}{ Jiangxi } & Nov. & 1 & 1 & 1 & 0 & 1 & 0 & 0 & 0 \\
\hline & No. of positive & 29 & 28 & 29 & 19 & 28 & 5 & 0 & 1 \\
\hline & Winter & & & & & & & & 1 \\
\hline Hebei & Dec. & 1 & 1 & 1 & 1 & 1 & 0 & 0 & 0 \\
\hline Henan & Dec. & 1 & 1 & 1 & 0 & 1 & 0 & 0 & 0 \\
\hline Shaanxi & Dec. & 1 & 1 & 1 & 1 & 1 & 0 & 0 & 1 \\
\hline Shandong & Dec. & 1 & 1 & 1 & 0 & 1 & 0 & 0 & 0 \\
\hline Fujian & Dec. & 1 & 1 & 1 & 1 & 1 & 0 & 0 & 0 \\
\hline Guangdong & Dec. & 1 & 1 & 1 & 0 & 1 & 0 & 0 & 1 \\
\hline Guizhou & Dec. & 1 & 1 & 1 & 1 & 1 & 0 & 0 & 0 \\
\hline Jiangsu & Dec. & 1 & 1 & 1 & 1 & 1 & 0 & 0 & 1 \\
\hline Sichuan & Dec. & 1 & 1 & 1 & 1 & 1 & 0 & 0 & 1 \\
\hline Beijing & Jan. & 1 & 1 & 1 & 1 & 1 & 0 & 0 & 0 \\
\hline Henan & Jan. & 1 & 1 & 1 & 0 & 1 & 0 & 0 & 1 \\
\hline Shaanxi & Jan. & 1 & 1 & 1 & 1 & 1 & 0 & 0 & 0 \\
\hline Shandong & Jan. & 1 & 1 & 1 & 0 & 1 & 0 & 0 & 1 \\
\hline Fujian & Jan. & 1 & 1 & 1 & 1 & 1 & 1 & 0 & 1 \\
\hline Guangdong & Jan. & 1 & 1 & 1 & 1 & 1 & 0 & 0 & 1 \\
\hline Guizhou & Jan. & 1 & 1 & 1 & 1 & 1 & 0 & 0 & 0 \\
\hline Sichuan & Jan. & 1 & 1 & 1 & 1 & 1 & 0 & 0 & 0 \\
\hline Zhejiang & Jan. & 1 & 1 & 1 & 0 & 1 & 0 & 0 & 1 \\
\hline Hebei & Feb. & 1 & 1 & 1 & 1 & 1 & 0 & 0 & 0 \\
\hline Henan & Feb. & 1 & 1 & 1 & 0 & 1 & 0 & 0 & 0 \\
\hline Shaanxi & Feb. & 1 & 1 & 1 & 1 & 1 & 0 & 0 & 0 \\
\hline Shandong & Feb. & 1 & 0 & 1 & 0 & 1 & 0 & 0 & 0 \\
\hline Shanxi & Feb. & 1 & 1 & 0 & 1 & 0 & 0 & 0 & 0 \\
\hline Fujian & Feb. & 1 & 1 & 1 & 1 & 1 & 0 & 0 & 0 \\
\hline Guangdong & Feb. & 1 & 1 & 1 & 0 & 1 & 0 & 0 & 0 \\
\hline Hubei & Feb. & 1 & 1 & 1 & 1 & 1 & 0 & 0 & 1 \\
\hline Jiangsu & Feb. & 1 & 1 & 1 & 0 & 1 & 0 & 0 & 0 \\
\hline \multirow[t]{2}{*}{ Sichuan } & Feb. & 1 & 1 & 1 & 1 & 1 & 0 & 0 & 0 \\
\hline & No. of positive & 28 & 27 & 27 & 18 & 27 & 1 & 0 & \\
\hline
\end{tabular}

